\title{
PERBAIKAN KUALITAS PRODUK ENTERTAINMENT CABINET HOWARD MILLER DENGAN PENDEKATAN SIX SIGMA DI PT. SINGATA FURNITURE
}

\author{
Gatot Basuki HM. \\ Jurusan Teknik Perkapalan, Fakultas Teknik Kelautan dan Mineral \\ Institut Teknologi Adhi Tama Surabaya \\ Jln. Arief Rachman Hakim 100 Surabaya Telp. (031) 5945043 \\ gatotbasukihm@itats.ac.id
}

\begin{abstract}
Abstrak
Persaingan usaha manufaktur semakin ketat. Faktor kualitas menjadi prioritas utama yang harus dijaga dalam proses produksi. PT. Singata Furniture merupakan salah satu perusahaan furniture yang berorientasi eksport. Salah satu produknya adalah entertainment cabinet howard miller. Namun dalam proses produksinya sering terjadi kecacatan produk yang disebabkan oleh banyak faktor yang belum mendapatkan solusi untuk memperbaikinya. Dengan pendekatan six sigma melalui penerapan DMAIC (Define, Measure, Analyze, Improve, Control) diharapkan dapat menganalisis faktor-faktor penyebab kecacatan yang terjadi dan memberikan usulan perbaikan sehingga dapat meningkatkan kualitas produksi. Hasil penelitian menunjukan terdapat 4 kriteria cacat yaitu salah potong, pecah, veneer menggelembung dan chipping coating. Dari hasil pengujian awal terhadap hasil produksi diperoleh nilai DMPO sebesar 15.716 dengan level sigma 3,68. Persentase cacat terbesar adalah cacat salah potong sebesar 36,8\%. Kemudian cacat chipping coating sebesar $22,6 \%$, cacat pecah $21,8 \%$ dan cacat veneer menggelembung sebesar $18,8 \%$.Usulan perbaikan yaitu pengecekan MC kayu $12 \%$, pengecekan density lem veneer dan permukaan roll, penyetelan mortizer harus simetris, aplikasi pencampuran cat sesuai dengan coating sheet. Nilai level sigma setelah tindakan perbaikan diperoleh sebesar 3,92.
\end{abstract}

\section{PENDAHULUAN}

Kualitas merupakan suatu hal yang sangat penting dalam proses pembuatan produk. semakin tingginya persaingan usaha di dunia industri manufaktur, mendorong para pelaku industri harus meningkatkan kualitas dalam menghasilkan produk. Ini dilakukan untuk menjaga eksistensi dalam merebut persaingan dan pangsa pasar eksport. Menurut (Vincent Gaspersz, 2002) kualitas adalah sebagai konsistensi peningkatan dan penurunan variasi karakteristik produk, agar dapat memenuhi spesifikasi dan kebutuhan, guna meningkatkan kepuasan pelanggan internal maupun eksternal.

Produk furniture indonesia sudah diakui kualitasnya diluar negeri seperti Amerika Serikat dan Jerman. PT. Singata Furniture merupakan salah satu industri furniture di Sidoarjo yang mempunyai buyer seperti howard miller dan hammary Furniture, kedua buyer tersebut merupakan brand ternama yang mempunyai desain dengan karakteristik klasik. Dalam proses produksinya PT. Singata Furniture sering mengalami cacat produksi. Misal salah potong dan pengemboran yang dilakukan oleh operator. Cacat dalam proses assembling yang mengakibatkan bahan tidak bisa dirakit, cacat dalam proses finishingseperti bubble coating, chippingsehingga harus dilakukan proses finishing ulang untuk menghasilkan warna yang sesuai. Masalah dalam proses tersebut dapat mengakibatkan kerugian bagi perusahaan baik material maupun biaya produksi. hal ini berdampak pada kerugian perusahaan baik jangka pendek dan jangka panjang karena dianggap melakukan pemborosan sumber daya yang dimiliki perusahaan.

Strategi penerapan six sigma yang diciptakan oleh DR. Mikel Harry dan Richard Schroeder disebut 
sebagai The Six Sigma Breakthrough Strategy. Strategi ini merupakan metode sistematis yang menggunakan pengumpulan data dan analisis statistik untuk menentukan sumber-sumber variasi dan cara-cara untuk menghilangkannya (Harry dan Scroeder, 2000).Six sigma metode memiliki banyak nilai-nilai dasar seperti prinsip-prinsip perbaikan proses, metode statistik, manajemen sistem, perbaikan terus-menerus dan perbaikan terkait keuangan (Rimantho, 2017).

DMAIC digunakan untuk meningkatkan proses bisnis yang telah ada, sedangkan DMADV digunakan untuk menciptakan desain proses baru dan atau design produk baru dalam cara sedemikian rupa agar menghasilkan zero defect (Gaspersz, 2011). Menurut Hendardi (2006) Untuk meningkatkan kualitas produk maka dapat menggunakan perbaikan dengan metode Six Sigma yaitu dengan menggunakan pendekatan DMAIC (Define, Measure, Analyze, Improve and Control). Metode DMAIC banyak digunakan pada program Six Sigma di perusahaan kecil menengah di Inggris dan memberikan hasil yang memuaskan (Antony, 2005) dan secara tradisional metode ini banyak diterapkan oleh tim Six Sigma dalam melakukan perbaikan untuk mencapai tingkat enam sigma (Thomas, 2006). Dengan pendekatan DMAIC diharapkan dapat memperbaiki dan meningkatkan kualitas dari produk furniture tersebut. Adapun alat bantu yang digunakan (flowchart, fishbone, check sheet, histogram, pareto, control chart, scatter plot). Dengan menggunakan alat - alat bantu tersebut diharapkan mampu mengurangi defect dan meningkatkan kualitas produk Entertainment Cabinet Howard Miller di PT. Singata Furniture.

\section{TINJAUAN PUSTAKA}

Siklus DMAIC (Define, Measure, Analyze, Improve and Control)

DMAIC merupakan proses perbaikan untuk peningkatan terus menerus menuju target Six Sigma. Proses ini menghilangkan langkah-langkah proses yang tidak produktif, sering berfokus pada pengukuran-pengukuran baru, dan menetapkan teknologi untuk peningkatan kualitas. Penggunaan DMAIC dapat diterapkan baik pada usaha perbaikan proses maupun pada desain atau desain ulang proses.
1. Define (D) merupakan langkah operasional pertama dalam program peningkatan kualitas Six Sigma yaitu identifikasi produk atau proses yang akan diperbaiki.

2. Measure $(M)$ merupakan langkah operasional kedua dalam program peningkatan kualitas Six Sigma yaitu melakukan pengumpulan data melalui pengukuran yang dapat dilakukan pada tingkat proses, output.

3. Analyze (A) merupakan langkah operasional ketiga dalam program peningkatan kualitas Six Sigma yaitu mengidentifikasi sumber - sumber dan akar penyebab kecacatan atau kegagalan.

4. Improve (I). Pada tahap ini ditetapkan suatu rencana tindakan (action plan) untuk melaksanakan peningkatan kualitas SixSigma.

5. Control $(C)$. Pada tahap ini hasil peningkatan kualitas didokumentasikan dan disebarluaskan, prosedur-prosedur didokumentasikan dan dijadikan pedoman kerja standar.

\section{Kapabilitas Proses}

Kapabilitas proses merupakan suatu ukuran kinerja kritis yang menunjukkan proses tersebut mampu menghasilkan sesuai dengan spesifikasi produk yang ditetapkan oleh manajemen berdasarkan kebutuhan dan ekspektasi pelanggan. Data atribut merupakan data kualitatif yang dihitung menggunakan daftar pencacahan atau tally untuk keperluan pencatatan analisis. Manfaat yang diperoleh dari analisis kapabiliti proses adalah sebagai berikut:

1. Membantu perancang produk dalam memilih atau mengubah proses.

2. Mengurangi variasi proses produksi.

3. Mengetahui seberapa baik suatu proses dapat memenuhi toleransi.

4. Merencanakan urutan proses produksi apabila ada pengaruh interaktif proses padatoleransi.

Dalam konteks pengendalian proses statistik dikenal dua jenis data atribut, yaitu:

1. Defect per opportunity (DPO) Ukuran kegagalan yang dihitung dalam program peningkatan kualitas Six Sigma yang menunjukkan banyaknya cacat atau kegagalan per satu kesempatan.

$$
\mathrm{DPO}=\frac{\text { Banyaknya Cacat yang ditemukan }}{\text { Banyaknya Unit yang Diperiksa x CTQ Potensial }} . \text { (1) }
$$


2. Defect per million opportunity (DPMO) Ukuran kegagalan dalam program peningkatan kualitas Six Sigma yang menunjukkan kegagalan per sejuta kesempatan.

$$
\mathrm{DPMO}=\mathrm{DPO} \times 1.000 .000
$$

\section{METODE PENELITIAN}

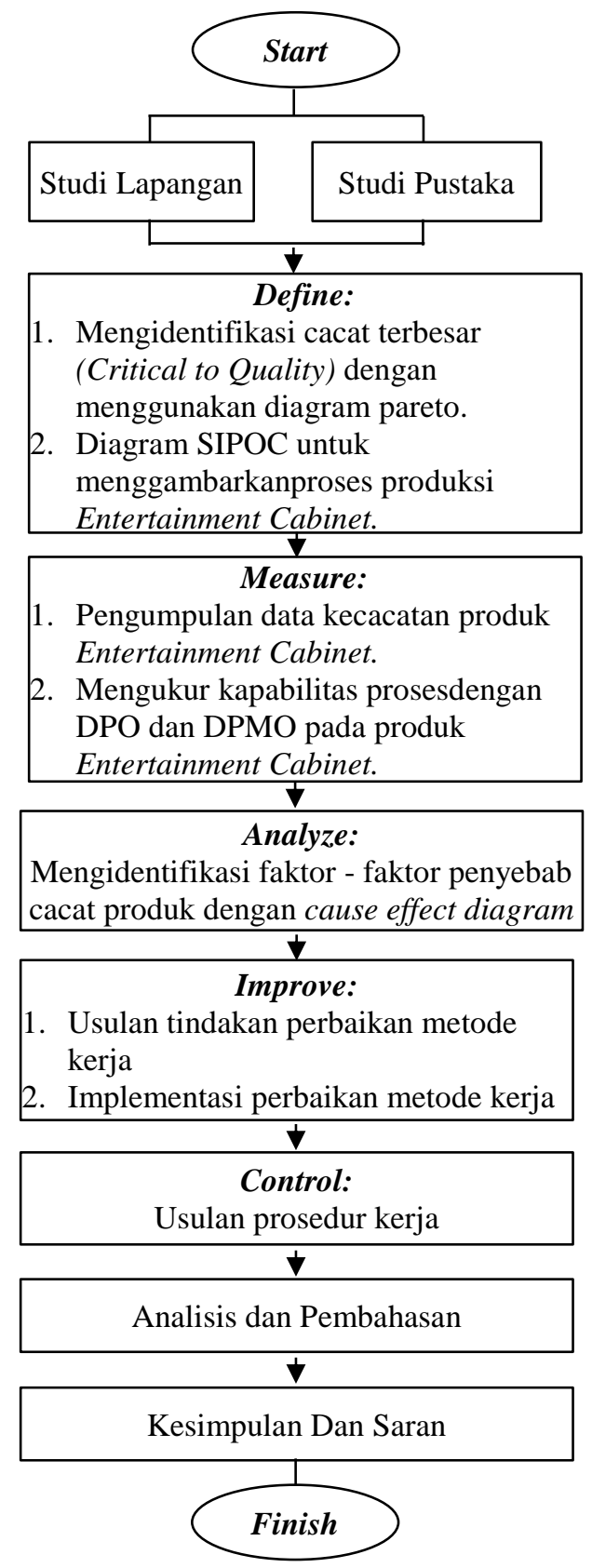

Gambar 1. Diagram Blok Penelitian

\section{HASIL DAN PEMBAHASAN}

Pengumpulan data diambil dengan melakukan survey dan mencari permasalahan yang timbul saat proses produksi berlangsungdan untuk pengolahan data denganmenggunakan metode DMAIC (Define, Measure, Analyse, Improve, Control).

\section{Define}

Pelaksanaan inspeksi dilakukan oleh perusahaan melalui Quality Control masing-masing departemen. Langkah awal yang harus diperhatikan adalah penentuan pendefinisian CTQ (Critical to Quality), untuk mengetahui karakteristik kualitas waktu pengamatan dilakukan selama 12 bulan terhadap proses produksi produk Entertainment Cabinet Howard Miller.Jenis cacat yang sering terjadi yaitu seperti salah potong pada proses cuttingyaitu pemotongan komponen yang tidak sesuai dengan ukuran yang ada pada cutting list produk. Adanya pecah pada proses assembling body saat merakit komponen ini terjadi karena ukuran lubang dowel atau mortizer tidak sesuai dengan pasangannya sehingga saat dimasukan terjadi retak pada ujung komponen yang mengakibatkan pecah. Hasil tempelan veneer yang menggelembung pada top table disebabkan oleh pemberian lem pada proses penempelan bahan veneer dengan MDF tidak merata sehingga hasil proses pengepresan tidak maksimal. Chipping coating pada proses finishing terjadi karena banyaknya debu atau material yang menempel saat proses pengecetan berlangsung, sehingga hasil coating menjadi kasar yang menempel pada top table dan side table.Dari hasil pengamatan tersebut maka dapat ditetapkan jumlah CTQ (Critical to Quality) adalah 4 dan selanjutnya digunakan untuk menentukan nilai DPMO dan level sigma. Hasil pengamatan cacat produksi terhadap produk Entertainment Cabinet ditunjukan pada tabel 1. 
Tabel 1. Cacat Produksi Produk Entertainment Cabinet Howard Miller

\begin{tabular}{|ll|c|c|cc|c|c|}
\hline No. & Bulan & $\begin{array}{c}\text { Produksi } \\
\text { (Unit) }\end{array}$ & $\begin{array}{c}\text { Salah } \\
\text { Potong }\end{array}$ & Pecah $\begin{array}{c}\text { Jenis Cacat } \\
\text { Veneer } \\
\text { menggelembung }\end{array}$ & $\begin{array}{c}\text { Chipping } \\
\text { Coucting }\end{array}$ & $\begin{array}{c}\text { Total } \\
\text { Produk } \\
\text { Cacat } \\
\text { (Unit) }\end{array}$ \\
\hline 1 & Januari & 243 & 7 & 3 & 3 & 4 & 17 \\
2 & Pebruari & 368 & 5 & 2 & 0 & 3 & 10 \\
\hline 3 & Maret & 297 & 3 & 2 & 2 & 2 & 9 \\
4 & April & 241 & 2 & 1 & 1 & 5 & 9 \\
\hline 5 & Mei & 139 & 2 & 3 & 6 & 3 & 14 \\
6 & Juni & 197 & 3 & 4 & 3 & 3 & 13 \\
7 & Juli & 201 & 8 & 3 & 3 & 2 & 16 \\
\hline 8 & A gustus & 182 & 5 & 1 & 2 & 2 & 10 \\
9 & September & 124 & 6 & 2 & 1 & 3 & 12 \\
\hline 10 & Oktober & 99 & 3 & 1 & 1 & 0 & 5 \\
11 & November & 107 & 3 & 4 & 3 & 1 & 11 \\
\hline 12 & Desember & 183 & 2 & 3 & 0 & 2 & 7 \\
& Total & 2.381 & 49 & 29 & 25 & 30 & 133 \\
\hline \multicolumn{2}{|c|}{ Rata-rata } & 198 & 4,08 & 2,42 & 2,08 & 2,50 & 11,08
\end{tabular}

Setelah diperoleh jumlah cacat produk Entertainment Cabinet maka dilakukan uji kecukupan data dimana nilai $\mathrm{N}^{\prime}<\mathrm{N}$ berarti data yang telah diambil telah mencukupi, Akan tetapi jika N'> N artinya data belum mencukupi untuk dilakukan analisis.

Berdasarkan data pengamatan dapat diketahui bahwa dari total jumlah produksi yang dihasilkan sebanyak 2.381 unit selama 12 bulan didapatkan total produk cacat Entertaiment Cabinet sebanyak 133 unit, sedangkan peneliti mengasumsikan Tingkat Ketelitian 5\% berarti $\mathrm{s}=0,05$ dan Tingkat Kepercayaan $99 \%$ berarti $\mathrm{k}=3$.

$\mathrm{p}=\frac{\sum \text { Produk Cacat }}{\sum \text { Sample yang diperiksa }}$

$\mathrm{p}=\frac{133}{2381}=0,0559$

Setelah mengetahui nilai $\mathrm{p}=0,0559$, maka dilakukan uji kecukupan data (N') dengan menggunakan rumus :

$\mathrm{N}^{\prime}=\frac{k^{2}}{s^{2}} \times p(1-p)$

$\mathrm{N}^{\prime}=\frac{3^{2}}{0,05^{2}} \times 0,0559(1-0,0559)=189,86$

Karena nilai $\mathrm{N}^{\prime}<\mathrm{N}=189,86<2.381$ maka data pengamatan telah mencukupi.
Setelah mengetahui nilai - nilai tersebut, dibuat sebuah peta kendali dimana pada peta kendali tersebut akan terlihat adanya nilai setiap periodik pengukuran tingkat kecacatan produk Entertainment Cabinet Howard Miller.

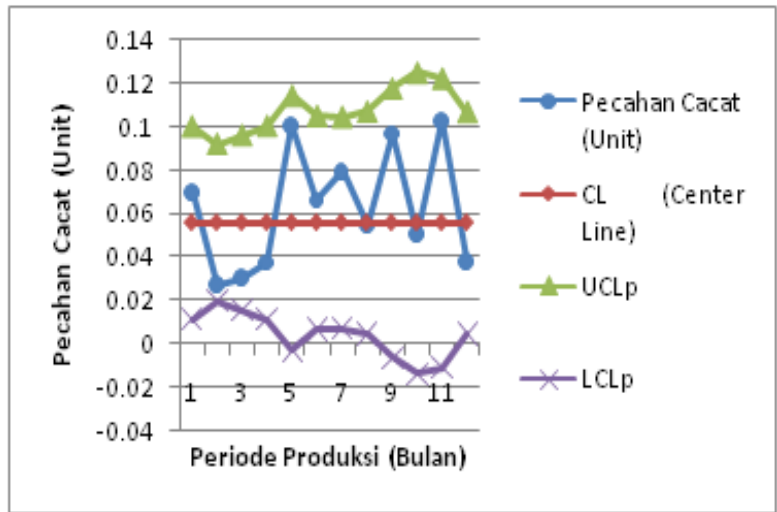

Gambar 2. Peta Kendali Produk Entertainment Cabinet Howard Miller

Untuk mengetahui seberapa besar tingkat kecacatan pada produk Entertainment Cabinet dapat digambarkan dengan menggunakan diagram Pareto (Pareto chart) seperti sebagaimana disajikan pada Gambar 2.

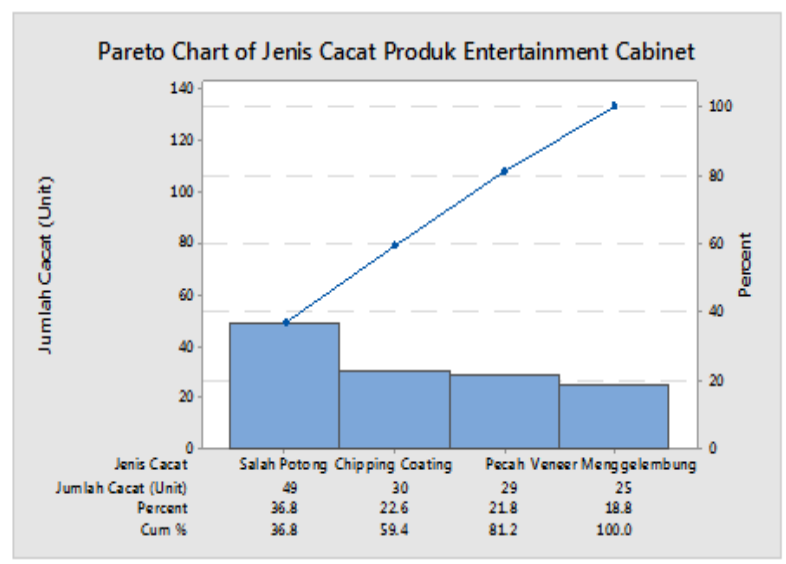

Gambar 2. Pareto Chart Cacat produksi Produk Entertainment Cabinet

Dari pareto chart tersebut dapat dilihat bahwa persentase tertinggi adalah cacat salah potong sebesar $36,8 \%$. Kemudian cacat chipping coating 
sebesar 22,6\%, cacat pecah $21,8 \%$ dan cacat veneer menggelembung sebesar $18,8 \%$.

\section{Measure}

Pada tahap measure ini merupakan tahap kedua dalam peningkatan kualitas Six Sigma. Tahap ini akan dilakukan pengukuran DPMO serta Level sigma. Berdasarkan data jumlah kecacatan, total produksi dan jenis cacat seperti salah potong, pecah, veneer menggelembung, shipping coating akan dilakukan pengukuran kinerja produksi produk Entertainment Cabinet, yaitu dengan menghitung DPMO dan nilai sigma setiap periode. Hasil perhitungan DPMO dan Level Sigma ditunjukan pada tabel 2.

Tabel 2. Perhitungan DPMO dan LevelSigma

\begin{tabular}{|c|c|c|c|c|}
\hline Bulan & $\begin{array}{l}\text { Produksi } \\
\text { (Unit) }\end{array}$ & $\begin{array}{c}\text { Jumlah Cacat } \\
\text { (Unit) }\end{array}$ & $\begin{array}{c}\text { Nilai } \\
\text { DPMO }\end{array}$ & Level Sigma \\
\hline Januari & 243 & 17 & $17.489,71$ & 3,6086 \\
\hline Pebrvari & 368 & 10 & $6.793,48$ & 3,9680 \\
\hline Maret & 297 & 9 & $7.575,76$ & 3,9287 \\
\hline April & 241 & 9 & $9.336,10$ & 3,8520 \\
\hline Mei & 139 & 14 & 25.179 .86 & 3.4569 \\
\hline Juni & 197 & 13 & $16.497,46$ & 3,6321 \\
\hline Juli & 201 & 16 & 19.900 .50 & 3.5558 \\
\hline Agustus & 182 & 10 & 13.736 .26 & 3,7047 \\
\hline September & 124 & 12 & 24.193 .55 & 3,4740 \\
\hline Oktober & 99 & 5 & $12.626,26$ & 3,7375 \\
\hline Nopember & 107 & 11 & $25.700,93$ & 3,4481 \\
\hline Desember & 183 & 7 & $9.562,84$ & 3,8431 \\
\hline Total & 2.381 & 133 & $188.592,71$ & 44,2096 \\
\hline Rata-rata & 198,42 & 11,08 & $15.716,06$ & 3,6841 \\
\hline
\end{tabular}

Sesuai hasil perhitungan maka dapat diketahui bahwa rata-rata nilai level sigma adalah 3,68. Langkah selanjutnya yaitu mencari penyebab permasalahan yang terjadi terhadap terjadinya cacat tersebut diatas.

\section{Analyze}

Pada tahap analyze ini merupakan langkah yang memperhatikan sesuai fakta dari proses produksiproduk Entertainment Cabinet, lalu menganalisa penyebab kegagalan produk atau terjadinya cacat produk. dengan menggunakan diagram sebab akibat dapat diketahui faktor-faktor penyebab terjadinya cacat pada produk Entertainment Cabinet. Penyebab terjadinya cacat tersebut dapat dilihat pada gambar 3 .

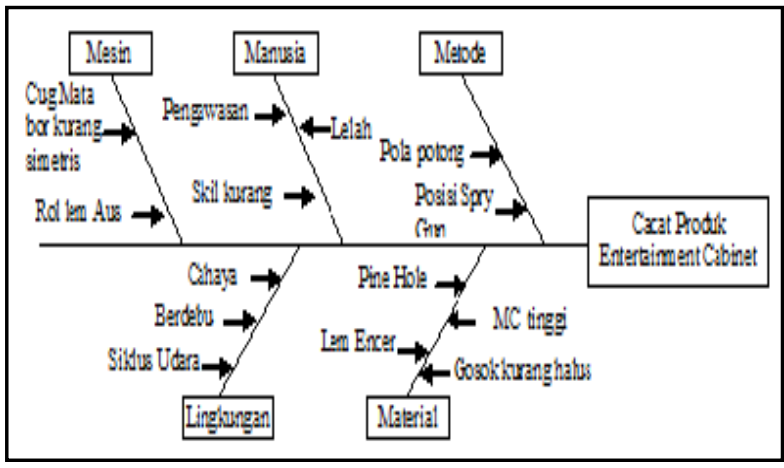

Gambar 3. Diagram Sebab Akibat Cacat Produk Entertainment Cabinet

\section{Improve}

Pada tahap Improve dilakukan setelah sumbersumber dan akar penyebab dari masalah kualitas terindentifikasi. Pada tahap ini ditetapkan suatu rencana tindakan (action plan) untuk melaksanakan peningkatan kualitas Six sigma. Penerapan rencana tindakan perbaikan menggunakan FMEA (Failure Mode and Effect Analysis) yaitu Potential failure mode (identifikasi kegagalan modus potensial), Pada tahap ini dilakukan identifikasi masalah-masalah penyebab kecacatan, 2) Potential effect(s)of failure (identifikasi akibat kegagalan),3) Potential cause(s) of failure (identifikasi penyebab kegagalan. Dengan mengacu pada tingkat Risk Priority Number (RPN) adalah ukuran yang digunakan ketika menilai risiko untuk membantu mengidentifikasi "critical failure modes" terkait dengan desain atau proses, maka dapat dibuat tabel prioritas usulan tindakan.

Tabel 3. Prioritas Usulan Tindakan perbaikan

Cacat Produk Entertainment Cabinet

\begin{tabular}{|c|l|l|l|}
\hline Prioritas & $\begin{array}{l}\text { Penyebab } \\
\text { Potensial } \\
\text { (Potensial } \\
\text { Cause) }\end{array}$ & RPN & \multicolumn{1}{|c|}{$\begin{array}{c}\text { Recommended } \\
\text { Action }\end{array}$} \\
\hline 1 & $\begin{array}{l}\text { MC kayu } \\
\text { tinggi }\end{array}$ & 247 & $\begin{array}{l}\text { Pengecekan MC } \\
\text { kayu sebelum keluar } \\
\text { Kiln Dry dengan } \\
\text { kadar MC dibawah } \\
12 \% .\end{array}$ \\
\hline 2 & $\begin{array}{l}\text { Tempelan } \\
\text { veneer } \\
\text { menggelemb } \\
\text { ung }\end{array}$ & 192 & $\begin{array}{l}\text { Pengecekan density } \\
\text { lem veneer sebelum } \\
\text { dipakai, tekstur } \\
\text { bahan veneer tidak }\end{array}$ \\
\hline
\end{tabular}




\begin{tabular}{|l|l|l|l|}
\hline & & & $\begin{array}{l}\text { boleh terlalu kering } \\
\text { dan bergelombang. } \\
\text { Penggunaan roll } \\
\text { harus merata. }\end{array}$ \\
\hline 3 & $\begin{array}{l}\text { Lubang bor } \\
\text { Mortizer } \\
\text { pecah saat } \\
\text { dirakit }\end{array}$ & 186 & $\begin{array}{l}\text { Sudut mata pisau } \\
\text { harus simetris } \\
\text { dengan komponen, } \\
\text { speelling dengan } \\
\text { lubang mortizer 0,2 } \\
\text { mm. kedalaman } \\
\text { lubang bor harus } \\
\text { selisih 3 mm. }\end{array}$ \\
\hline $\begin{array}{l}\text { Warna } \\
\text { chipping } \\
\text { pada top } \\
\text { tabel dan } \\
\text { side tabel. }\end{array}$ & 173 & $\begin{array}{l}\text { Aplikasi bahan } \\
\text { coating harus sesuai } \\
\text { coating sheet, suhu } \\
\text { ruangan diatas 28 } \\
\text { derajat celcius, lantai } \\
\text { finishing harus } \\
\text { bersih dari kotoran } \\
\text { dan debu, sanding } \\
\text { finish harus merata. }\end{array}$ \\
\hline
\end{tabular}

Setelah perbaikan dilakukan pengamatan dilakukan kembali terhadap produk Entertainment Cabinet dengan sampel 196 unit setiap kali pengamatan yang dilakukan selama 6 hari kerja. Jumlah cacat ditemukan sebanyak 6 unit, langkah ini dilakukan untuk membandingkan hasil perbaikan dengan sebelumnya maka dihitung kembali DPO, DPMO dan Level sigma sebagai berikut:

$\mathrm{DPO}=\frac{\text { Jumlah Cacat }}{\text { Unit } x \text { peluang }}$

$\mathrm{DPO}=\frac{6}{196 \times 4}=0,00765$

$\mathrm{DPMO}=0,00765 \times 1.000 .000=7.653$

Selanjutnya untuk mendapatkan nilai level sigma perhitungan menggunakan microsoft office excel dengan formulasi sebagai berikut:

Sigma $=\quad \operatorname{NORMSINV}((1000000$ DPMO)/1000000)+1.5

Sigma $=3,92$

Setelah tindakan perbaikan dilakukan maka dapat diperoleh nilai DPMO sebesar 12.500 dengan level sigma 3,92 dibandingkan sebelum adanya tindakan perbaikan proses produksi entertainment cabinet howard millernilai level sigma3,68. Hal ini menunjukan bahwa tindakan perbaikan yang telah dilakukan dapat mengurangi tingkat kecacatan pada produk entertainment cabinet howard miller.

\section{KESIMPULAN}

Berdasarkan hasil analisis yang dilakukan dengan menggunakan six sigma terhadap proses produksi entertainment cabinet howard miller adalah sebagai berikut:

1. Persentase cacat terbesar adalah pada cacat salah potong sebesar $36,8 \%$. Kemudian cacat chipping coating sebesar $22,6 \%$, cacat pecah $21,8 \%$ dan cacat veneer menggelembung sebesar 18,8\%. Kapabilitas level sigma awal adalah 3,68.

2. Usulan perbaikan yang dilakukan untuk meminimalkan jumlah cacat untuk produk entertainment cabinet adalah Pengecekan MC kayu sebelum keluar Kiln Dry dengan kadar MC dibawah $12 \%$. Pengecekan density lem veneer sebelum dipakai, tekstur bahan veneer tidak boleh terlalu kering dan bergelombang. Penggunaan roll harus merata. Sudut mata pisau harus simetris dengan komponen, speelling dengan lubang mortizer $0,2 \mathrm{~mm}$. kedalaman lubang bor harus selisih 3 mm.Aplikasi bahan coating harus sesuai coating sheet, suhu ruangan diatas 28 derajat celcius, lantai finishing harus bersih dari kotoran dan debu, sanding finish harus merata.Level sigma setelah tindakan perbaikan sebesar 3,92.

\section{DAFTAR PUSTAKA}

Hendradi, C. Tri. 2006.Statistik SIX SIGMA dengan MINITAB, Penerbit Andi, Yogyakarta.

Vincent Gaspersz.2002. Pedoman Implementasi Program Six Sigma, Penerbit Gramedia Pustaka Utama, Jakarta.

Antony, J. Kumar, M., Madu, C. N.2005. Six sigma in small-and-medium-sized $U K$ manufacturing enterprises: some empirical observations, International Journal of Quality \& Reliability Management, Vol. 22, No. 8: 860-874. 
Jurnal MATRIK

Volume XIX No.1, September 2018, p 1-7

Thomas, A., Barton, R.2006. Developing an SME based six sigma strategy, Journal of Manufacturing Technology Management, Vol. 17, No. 4: 417-434.

Harry, M., dan Schroeder, R. 2000. Six Sigma : The Breakthrough Management Strategy Revolutionizing The World's Corporations, Currency Doubleday, New York.

Rimantho Dino, Mariani Made D. 2017. Penerapan Metode Six Sigma Pada Pengendalian Kualitas Air Baku Pada Produksi Makanan, Jurnal Ilmiah Teknik Industri UMS, p-ISSN 1412-6869 e-ISSN 2460-4038. 